\title{
Relationship of carbon dioxide tension in arterial blood to pulmonary wedge pressure in heart failure
}

\author{
G. Lorenzi-Filho*, E.R. Azevedo\#, J.D. Parker", T.D. Bradley*
}

Relationship of carbon dioxide tension in arterial blood to pulmonary wedge pressure in heart failure. G. Lorenzi-Filho, E.R. Azevedo, J.D. Parker, T.D. Bradley. (C)ERS Journals Ltd 2002.

ABSTRACT: Hypocapnia contributes to the genesis of Cheyne-Stokes respiration and central sleep apnoea in patients with congestive heart failure (CHF) and is associated with increased mortality. However, the cause of hypocapnia in patients with chronic stable CHF is unknown. Since pulmonary congestion can induce hyperventilation via stimulation of pulmonary vagal afferents, the present study tested the hypothesis that in patients with CHF (carbon dioxide tension in arterial blood $\left.\left(\mathrm{P}_{\mathrm{a}}, \mathrm{CO}_{2}\right)\right)$ is inversely related to pulmonary capillary wedge pressure (PCWP), and that alterations in PCWP would cause inverse changes in $\mathrm{Pa}, \mathrm{CO}_{2}$.

In $11 \mathrm{CHF}$ patients undergoing diagnostic cardiac catheterization, haemodynamic variables and arterial blood gas tensions were measured simultaneously at baseline. In three patients, these measurements were repeated after coronary angiographic dye infusion and nitroglycerine infusion.

At baseline, $\mathrm{Pa}_{2}, \mathrm{CO}_{2}$ correlated inversely with $\mathrm{PCWP}(\mathrm{r}=-\mathbf{0 . 8 0}, \mathrm{p}=0.003)$. In the three patients in whom multiple measurements were made, acute alterations in PCWP caused inversely proportional changes in $\mathrm{Pa}, \mathrm{CO}_{2}$.

The present study concludes that in patients with congestive heart failure, pulmonary capillary wedge pressure is an important determinant of carbon dioxide tension in arterial blood. These findings imply that hypocapnia in patients with chronic stable congestive heart failure is a respiratory manifestation of elevated left ventricular filling pressures.

Eur Respir J 2002; 19: 37-40
Depts of Medicine of the *Toronto General and "Mount Sinai Hospitals/ University Health Network, University of Toronto, Toronto, Ontario, Canada.

Correspondence: T.D. Bradley, NU 9112 Toronto General Hospital/UHN, 200 Elizabeth Street, Toronto, ON, M5G 2C4, Canada.

Fax: 4163404197

Keywords: Arterial blood gas tensions cardiopulmonary interactions hypocapnia

Received: February 122001

Accepted after revision July 252001

The present study was supported by grants from the Canadian Institutes of Health Research (MOP-11607) and from the Heart and Stroke Foundation of Ontario. G. Lorenzi-Filho was supported by research fellowships from Fundacao de Amparo a Pesquisa do Estado de Sao Paulo, Brazil and the Dept of Medicine of the University of Toronto. E.R. Azevedo held a research fellowship from Astra Zeneca/Heart and Stroke Foundation of Canada. T.D. Bradley is a Senior Scientist of the Canadian Institutes of Health Research.
In patients with congestive heart failure (CHF), hypocapnia (i.e. carbon dioxide tension in arterial blood $\left.\left(\mathrm{Pa}_{\mathrm{a}}, \mathrm{CO}_{2}\right)<40 \mathrm{mmHg}\right)$ predisposes to ventilatory instability and leads to central apnoeas during sleep when $\mathrm{Pa}, \mathrm{CO}_{2}$ falls below the threshold for apnoea $[1,2]$. Indeed, CHF patients with Cheyne-Stokes respiration and central sleep apnoea (CSR-CSA) have lower $P$ a, $\mathrm{CO}_{2}$ both awake and asleep, than $\mathrm{CHF}$ patients without CSR-CSA [1]. The presence of CSR-CSA in patients with $\mathrm{CHF}$ is associated with increased mortality probably due to apnoea-related hypoxia, arousals from sleep and activation of the sympathetic nervous system [3, 4]. In addition, hypocapnia in patients with $\mathrm{CHF}$ is associated with an increased prevalence of ventricular arrhythmias [5], which also predisposes to sudden death. Despite these pathophysiological associations, however, the cause of hypocapnia in CHF remains to be elucidated.

In animals, increased pulmonary venous pressure induces hyperventilation through stimulation of pulmonary vagal afferents [6]. Therefore, one possible explanation for hypocapnia in $\mathrm{CHF}$ patients is that stimulation of pulmonary vagal afferents by high cardiac filling pressures or pulmonary congestion induces hyperventilation. However, only indirect evidence supports this possibility. For example, it has been shown that $\mathrm{CHF}$ patients with elevated pulmonary capillary wedge pressure (PCWP) have a significantly lower $\mathrm{Pa}_{\mathrm{a}} \mathrm{CO}_{2}$ than patients whose PCWP is normal [7]. Since oxygen tension in arterial blood $\left(\mathrm{Pa}, \mathrm{O}_{2}\right)$ is usually normal in such patients, hypoxia is not likely the cause of hypocapnia $[1,2,7]$. Based on these observations, it was hypothesized that in patients with chronic stable $\mathrm{CHF}, \mathrm{Pa}, \mathrm{CO}_{2}$ would be inversely related to PCWP and that alterations in PCWP would cause inverse changes in $\mathrm{Pa}, \mathrm{CO}_{2}$.

Methods

Subjects

The subjects were 11 consecutive males aged between $55-70$ yrs who were referred to the Heart 
Failure Clinic of the Mount Sinai Hospital, Toronto for diagnostic assessment of $\mathrm{CHF}$, and who were undergoing diagnostic cardiac catheterization. Entry criteria included a left ventricle ejection fraction at rest of $<35 \%$ measured by radionuclide angiography. One patient was in New York Heart Association functional class II and 10 were in class III. The aetiology of CHF was ischaemic in eight and idiopathic dilated cardiomyopathy in three patients. Medical therapy included diuretics in all 11 patients, angiotensinconverting enzyme inhibitors in eight, hydralazine in one, digoxin in six, and amiodarone in two. Patients with a history of respiratory disease were excluded.

\section{Protocol}

The protocol was approved by the institutional ethics committee and written informed consent was obtained from all patients. Diagnostic right and left heart catheterization, with patients awake and without sedation, was performed from the femoral approach. Right-sided heart catheterization was performed using a flotation catheter positioned in the right pulmonary artery. Prior to angiography, baseline measurements of pulmonary artery pressure, mean PCWP, and mean right atrial pressure were made using a water filled pressure transducer, and cardiac output was measured by the Fick method. An arterial blood sample was drawn simultaneously from the femoral arterial line for analysis of blood gas tensions. In the last three patients simultaneous measurements of PCWP and arterial blood gas tensions were made immediately after angiographic dye infusion, which caused an increase in PCWP, and during nitroglycerine infusion once PCWP had fallen by at least $15 \%$. Nitroglycerine was infused at a rate of $0.8-1.0 \mathrm{mg} \cdot \mathrm{kg} \cdot \mathrm{min}^{-}$. Throughout the procedures, patients breathed regularly.

\section{Statistical analysis}

To assess the potential relationships between $\mathrm{Pa}, \mathrm{CO}_{2}$ and a number of physiologically plausible determinants, a multiple stepwise linear regression analysis was carried out using $\mathrm{Pa}, \mathrm{O}_{2}$ alveolar-arterial $\mathrm{Pa}_{2} \mathrm{O}_{2}$ gradient, PCWP, right atrial pressure, mean arterial blood pressure and cardiac index as independent variables. A backward stepwise regression analysis was then performed to determine which of these variables was independently related to $\mathrm{Pa}, \mathrm{CO}_{2}$. Among the three patients in whom multiple arterial blood gas analyses were performed, repeated measures analysis of variance (ANOVA) was performed to determine whether altering PCWP caused any change in $\mathrm{Pa}, \mathrm{CO}_{2}$ and other variables. Changes in $\mathrm{Pa}_{2}, \mathrm{CO}_{2}$ were then plotted against changes in PCWP. A p-value $<0.05$ was considered statistically significant.

\section{Results}

Baseline characteristics of the patients are shown in table 1 . There were significant correlations between
Table 1.-Baseline characteristics of patients

\begin{tabular}{lc}
\hline Characteristics & All patients \\
\hline Age, yrs & $56 \pm 10$ \\
BMI, Kg·m & \\
LVEF $\%$ & $27.9 \pm 6.4$ \\
MAP mmHg & $21 \pm 9$ \\
Heart rate bpm & $87 \pm 17$ \\
RAP $\mathrm{mmHg}$ & $80 \pm 12$ \\
PCWP mmHg & $10 \pm 4$ \\
$\mathrm{CI}, \mathrm{L} / \mathrm{min} / \mathrm{m}^{2}$ & $20 \pm 5$ \\
pH & $19 \pm 0.3$ \\
$P \mathrm{a}, \mathrm{O}_{2} \mathrm{mmHg}$ & $7.43 \pm 0.06$ \\
$P \mathrm{a}, \mathrm{CO}_{2}, \mathrm{mmHg}$ & $79 \pm 18$ \\
$\mathrm{HCO}_{3}, \mathrm{mmol} \cdot \mathrm{L}^{-1}$ & $38 \pm 3$ \\
\end{tabular}

Data are presented as mean $\pm \mathrm{SD}$; BMI: body mass index; LVEF: left ventricular ejection fraction; MAP: mean arterial pressure; RAP: right atrial pressure; PCWP: pulmonary capillary wedge pressure; $\mathrm{CI}$ : cardiac index; bpm: beats per minute; $\mathrm{Pa}_{\mathrm{a}} \mathrm{O}_{2}$ : oxygen tension in arterial blood; $\mathrm{Pa}, \mathrm{CO}_{2}$ : carbon dioxide tension in arterial blood; $\mathrm{HCO}_{3}^{-}$: bicarbonate.

$\mathrm{Pa}_{\mathrm{a}} \mathrm{CO}_{2}$ and PCWP (r=-0.80, $\mathrm{p}=0.003$ ) (fig. 1), cardiac index $(\mathrm{r}=-0.71, \mathrm{p}=0.004)$ and right atrial pressure $(\mathrm{r}=-0.76, \mathrm{p}=0.008)$. However, even though two patients were mildly hypoxic $\left(\mathrm{Pa}, \mathrm{O}_{2}\right.$ of 58 and $\left.54 \mathrm{mmHg}\right)$ there were no significant correlations of $\mathrm{Pa}_{1} \mathrm{CO}_{2}$ with either $P a, O_{2} \quad(\mathrm{r}=0.14, \mathrm{p}=0.673)$ or alveolar-arterial partial pressure of $\mathrm{O}_{2}\left(\mathrm{PO}_{2}\right)$, gradient $(\mathrm{r}=-0.33, \mathrm{p}=0.325)$. Stepwise and backward linear regressions showed that PCWP was the only variable that correlated significantly and independently with $P$ a, $\mathrm{CO}_{2}$. Following dye infusions, PCWP increased (from 18.7 to 21.2, from 20.4 to 28.5 and from 29.0 to $34.0 \mathrm{mmHg}$ in the three subjects, respectively). During nitroglycerine infusions, PCWP consistently decreased (17.2, 18.0 and $18.0 \mathrm{mmHg}$, respectively). $P \mathrm{a}, \mathrm{CO}_{2}$ changed significantly in response to dye and nitroglycerine infusions (mean $\pm \mathrm{SD}, 39.7 \pm 2.1 \mathrm{mmHg}$ at baseline, to $36.3 \pm 0.6 \mathrm{mmHg}$ following dye, to $39.3 \pm 1.2 \mathrm{mmHg}$ during nitroglycerine infusions, $\mathrm{p}=0.03$, dye infusion different from the others). $P a, O_{2}$ were $72 \pm 16,81 \pm 14$

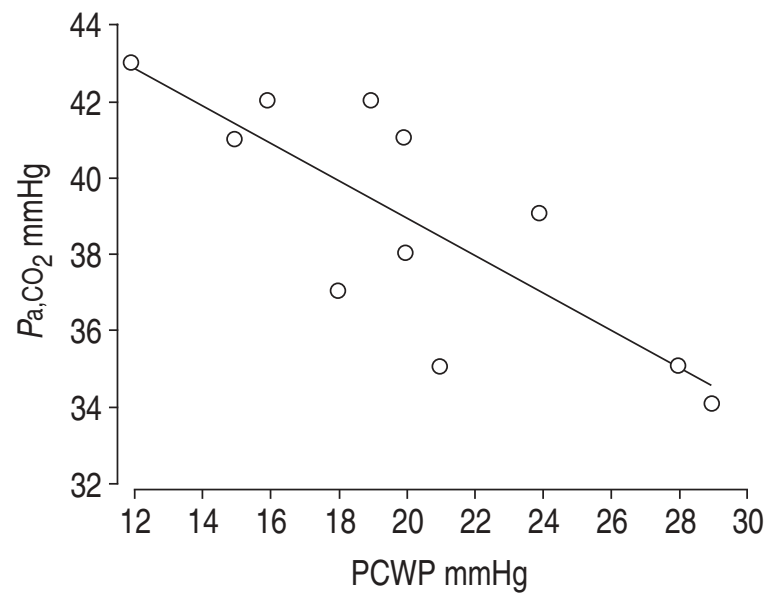

Fig. 1.- Relationship between carbon dioxide tension in arterial blood $\left(P \mathrm{a}, \mathrm{CO}_{2}\right)$ and pulmonary capillary wedge pressure (PCWP) for all 11 patients. $\mathrm{r}=0.80 ; \mathrm{p}=0.003$. 


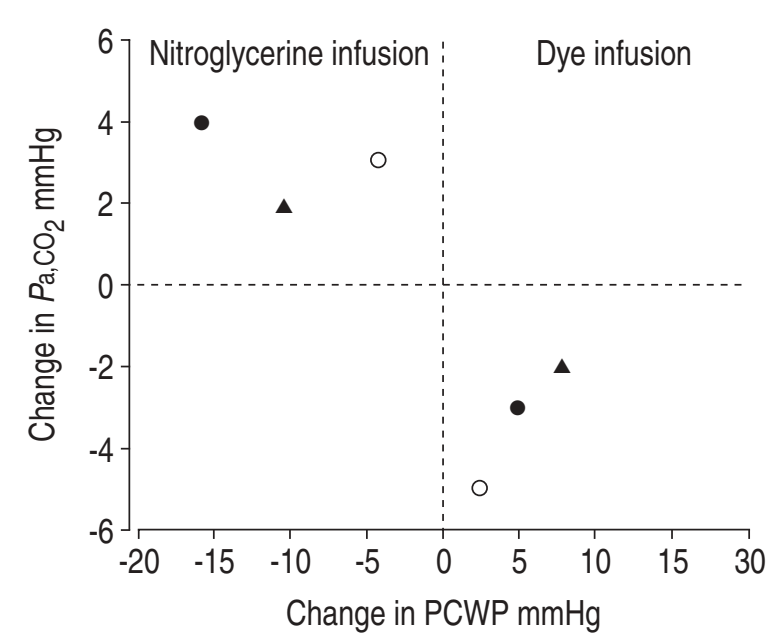

Fig. 2.-Acute changes in carbon dioxide tension in arterial blood $\left(P \mathrm{a}, \mathrm{CO}_{2}\right)$ as a function of acute variations in pulmonary capillary wedge pressure (PCWP) due to dye and nitroglycerine infusion in three patients. Data from the three patients are represented by the three different symbols.

and $71 \pm 18 \mathrm{mmHg}$ at baseline, after dye and during nitroglycerine infusions, respectively $(\mathrm{p}=0.13)$. Alveolar-arterial $P_{2}$ gradients were $38 \pm 17,33 \pm 14$ and $39 \pm 19 \mathrm{mmHg}$ at baseline, after dye and during nitroglycerine infusions, respectively $(\mathrm{p}=0.42)$.

There was a consistent inverse relationship between changes in $\mathrm{Pa}, \mathrm{CO}_{2}$ and changes in PCWP in response to dye and nitroglycerine infusions (fig. 2). Mean arterial blood pressures did not change significantly during the experiment $(94 \pm 29$ at baseline, to $102 \pm 23$ after dye infusion and to $87 \pm 11 \mathrm{mmHg}$ during nitroglycerine infusion respectively, $\mathrm{p}=0.17$ ).

\section{Discussion}

This study is the first in humans with $\mathrm{CHF}$ to demonstrate that PCWP is an independent determinant of $\mathrm{Pa}, \mathrm{CO}_{2}$. Evidence for this was provided by two novel observations. First, among all study subjects, there was a strong inverse relationship between $\mathrm{Pa}_{\mathrm{a}} \mathrm{CO}_{2}$ and PCWP. Second, when PCWP was raised by contrast dye infusion, $\mathrm{Pa}, \mathrm{CO}_{2}$ decreased. Conversely, when PCWP was reduced by nitroglycerine infusion, $P \mathrm{a}, \mathrm{CO}_{2}$ increased. Changes in $P \mathrm{a}, \mathrm{CO}_{2}$ were inversely proportional to changes in PCWP. These data indicate that elevated left ventricular filling pressure contributes to hypocapnia in patients with $\mathrm{CHF}$.

Hypocapnia plays a key role in the genesis of central apnoeas during CSR-CSA [1]. Central apnoeas during CSR-CSA are triggered by abrupt increases in ventilation and falls in $\mathrm{Pa}_{\mathrm{a}} \mathrm{CO}_{2}$ below the threshold for apnoea, which are abolished when $\mathrm{Pa}_{\mathrm{a}} \mathrm{CO}_{2}$ is raised by inhalation of a $\mathrm{CO}_{2}$ containing gas mixture during sleep [2]. Hypocapnia and CSR-CSA also have adverse clinical implications in patients with $\mathrm{CHF}$. They are associated with increased sympathetic nervous system activity [8], left ventricular volume [9], ventricular ectopy [5] and mortality [3, 4].

What causes hyperventilation in CHF? Hypoxia is one possibility. However, studies have consistently shown that hypocapnia in CHF patients with CSRCSA is not related to hypoxia during normal breathing $[1,5]$. The present findings agree with those observations: $P \mathrm{a}, \mathrm{O}_{2}$ was within normal limits in all except two patients, and $\mathrm{Pa}_{\mathrm{a}} \mathrm{CO}_{2}$ bore no significant relationship to $\mathrm{Pa}, \mathrm{O}_{2}$. In patients with CSR-CSA, hypoxia resulting from central apnoeas could lead to respiratory instability through stimulation of ventilation and consequent reductions in $\mathrm{Pa}, \mathrm{CO}_{2}$. However, it was demonstrated in the present study that inhalation of supplemental $\mathrm{O}_{2}$ sufficient to abolish apnoea-related hypoxia had no impact on either $P \mathrm{a}, \mathrm{CO}_{2}$ or on the frequency of central apnoeas [2]. Taken together, the above observations strongly suggest that in most patients with chronic stable $\mathrm{CHF}$, hypoxia is unlikely to play an important role in causing hypocapnia.

Increased chemosensitivity is another possible cause of hypocapnia in CHF. JAVAHERI [10] found that CHF patients with CSR-CSA had increased central chemosensitivity to $\mathrm{CO}_{2}$ compared to $\mathrm{CHF}$ patients without CSR-CSA. In addition, Solin et al. [11] found both increased central and peripheral sensitivity to $\mathrm{CO}_{2}$ in $\mathrm{CHF}$ patients with CSR-CSA. Furthermore, experimentally induced $\mathrm{CHF}$ has been shown to increase peripheral chemosensitivity [12]. These findings indicated that the state of cardiac failure itself can alter respiratory chemosensitivity. However, none of these studies examined the potential relationship between $\mathrm{Pa}, \mathrm{CO}_{2}$ and chemosensitivity, and between chemosensitivity and PCWP. Thus, it remains unclear whether increased chemosensitivity per se is a cause of hypocapnia in $\mathrm{CHF}$.

Another possible explanation for hypocapnia in $\mathrm{CHF}$ is stimulation of pulmonary vagal irritant receptors by pulmonary congestion. In animals, high pulmonary venous pressures induce tachypnoea, through stimulation of pulmonary vagal afferents [6]. However, the relationship between pulmonary venous pressure and $\mathrm{Pa}_{\mathrm{a}} \mathrm{CO}_{2}$ was not examined. In humans with CHF, Solin et al. [13] found a weak but significant inverse relationship between $P \mathrm{a}, \mathrm{CO}_{2}$ and PCWP $(\mathrm{r}=-0.4)$. However, measurements of PCWP and $\mathrm{Pa}_{2} \mathrm{CO}_{2}$ were performed several days to weeks apart, and no attempt was made to determine the effect of altering PCWP on $\mathrm{Pa}_{2}, \mathrm{CO}_{2}$. Consequently, they did not establish whether PCWP is an independent determinant of $\mathrm{Pa}, \mathrm{CO}_{2}$.

The demonstration of a significant inverse relationship between $\mathrm{Pa}_{2} \mathrm{CO}_{2}$ and PCWP in patients with $\mathrm{CHF}$ in the present study, support the findings of Solin et al. [13]. However, in the present study the findings of Solin et al. [13] are extended in several important ways. Firstly, haemodynamic measurements and arterial blood gas analyses were performed simultaneously. This probably accounts for the much stronger relationship between $\mathrm{Pa}_{\mathrm{a}} \mathrm{CO}_{2}$ and PCWP that was observed compared to Solin et al. [13]. Second, in contrast to SoLIN et al. [13], other potential influences on $\mathrm{Pa}, \mathrm{CO}_{2}$ were controlled, including cardiac output, right atrial pressure and $\mathrm{Pa}_{\mathrm{a}} \mathrm{O}_{2}$. Most importantly, however, the acute effects of altering PCWP on $\mathrm{Pa}, \mathrm{CO}_{2}$ were examined, demonstrating that PCWP contributes to variations in $\mathrm{Pa}_{\mathrm{a}} \mathrm{CO}_{2}$ independently of other 
potentially confounding variables, and that acute changes in PCWP caused proportional inverse changes in $P \mathrm{a}, \mathrm{CO}_{2}$. The demonstration that $\mathrm{Pa}, \mathrm{CO}_{2}$ varied as a function of PCWP supported a cause-effect relationship between these two variables. However, data on the effects of altering PCWP on $\mathrm{Pa}_{\mathrm{a}} \mathrm{CO}_{2}$ were obtained from only three subjects. This is because the local ethics review committee provided permission to infuse nitroglycerine to lower PCWP in only three subjects owing to the invasiveness and prolonged nature of the protocols they were undergoing (discussed later).

In order to determine what factors are associated with hypocapnia, the present authors had to include data from subjects with a wide range of $\mathrm{Pa}, \mathrm{CO}_{2}$ including some who were normocapnic. In previous studies, the present authors showed that $\mathrm{CHF}$ patients with CSR-CSA have lower $P \mathrm{a}, \mathrm{CO}_{2}$ than subjects without CSR-CSA, but that there is some overlap $[1,14]$. In general, patients with CSR-CSA have all awake $\mathrm{Pa}_{2} \mathrm{CO}_{2}$ or $<40 \mathrm{mmHg}$. Therefore, if hypocapnia is considered to be a $\mathrm{Pa}, \mathrm{CO}_{2}$ of $<40 \mathrm{mmHg}$, then six of the present patients were hypocapnic. More importantly, data from subjects with a lower $\mathrm{Pa}, \mathrm{CO}_{2}$ of $<40 \mathrm{mmHg}$ fall on the regression line in figure 1 .

Alterations in PCWP must have influenced $\mathrm{Pa}_{\mathrm{a}} \mathrm{CO}_{2}$ through the effect of left ventricular filling pressure and pulmonary venous pressure on respiratory pattern. Indeed, Churchill and Cope [6] showed that alterations in pulmonary venous pressure in dogs caused tachypnoea. However, in the present study it was not possible to assess respiratory rate and tidal volume during cardiac catheterization studies. This is because the protocol for the present study was carried out on patients who were undergoing another complex study lasting 3-4 h during which right and left heart catheters, a coronary artery sinus catheter and an intravenous infusion line were in place. Because of the extensive instrumentation, and the prolonged nature of the studies, it was not possible to apply additional instrumentation to measure respiratory pattern.

In summary, the results presented here demonstrate that elevated left ventricular filling pressure is a determinant of hypocapnia in patients with congestive heart failure. The results also indicate that alterations in pulmonary capillary wedge pressure cause inverse changes in the carbon dioxide tension in arterial blood. This cause-effect relationship is probably mediated through stimulation of pulmonary vagal irritant receptors by pulmonary venous congestion [6]. Further experiments will be required to test this hypothesis. Since hypocapnia plays a critical role in the genesis of central apnoeas in Cheyne-Stokes respiration and central sleep apnoea, one important implication of the present findings is that hypocapnia and Cheyne-Stokes respiration and central sleep apnoea are respiratory manifestations of high left ventricular filling pressures and pulmonary venous congestion in patients with congestive heart failure.

\section{References}

1. Naughton MT, Bernard D, Tam A. Rutherford R, Bradley TD. Role of hyperventilation in the pathogenesis of central sleep apnoeas in patients with congestive heart failure. Am Rev Respir Dis 1993; 148: 330-338.

2. Lorenzi-Filho G, Rankin F, Bies I, Merson R, Rosenberg JI, Bradley TD. Effects of inhaled $\mathrm{CO}_{2}$ and $\mathrm{O}_{2}$ on Cheyne-Stokes respiration in heart failure patients. Am J Respir Crit Care Med 1999; 159: 14901498.

3. Lanfranchi PA, Braghiroli A, Bosimini A, et al. Prognostic value of nocturnal Cheyne-Stokes respiration in chronic heart failure. Circulation 1999; 99: 1435-1440.

4. Sin DD, Logan AG, Fitzgerald FS, Liu PP, Bradley TD. Effects of continuous positive airway pressure on cardiovascular outcomes in heart failure patients with and without Cheyne-Stokes Respiration. Circulation 2000; 102: 61-66.

5. Javaheri $\mathrm{S}$, Corbett WS. Association of low $\mathrm{Pa}, \mathrm{CO}_{2}$ with central sleep apnoea and ventricular arrhythmias in ambulatory patients with stable heart failure. Ann Intern Med 1998; 128: 204-207.

6. Churchill ED, Cope O. The rapid shallow breathing resulting from pulmonary congestion and edema. J Exper Med 1929; 49: 531-537.

7. Bradley TD, Holloway RM, McLaughlin PR, Ross BL, Walters J, Liu PP. Cardiac output response to continuous positive airway pressure in congestive heart failure. Am Rev Respir Dis 1992; 145: 377382.

8. Naughton MT, Benard DC, Liu PP, Rutherford R, Rankin F, Bradley TD. Effects of nasal CPAP on sympathetic activity in patients with heart failure and central sleep apnoea. Am J Respir Crit Care Med 1995; 152: 473-479.

9. Tkacova R, Hall MJ, Liu PP, Fitzgerald FS, Bradley TD. Left ventricular volume in patients with heart failure and Cheyne-Stokes respiration during sleep. Am J Respir Crit Care Med 1997; 156: 1549-1555.

10. Javaheri S. A mechanism of central sleep apnoea in patients with heart failure. $N$ Eng J Med 1999; 341: 949-954.

11. Solin P, Roebuck T, Johns DP, Walters EH, Naughton MT. Peripheral and central ventilatory responses in central sleep apnoea with and without congestive heart failure. Am J Respir Crit Care Med 2000; 162: 2194-2200.

12. Sun SY, Wang W, Zucker IH, Schultz HD. Enhanced peripheral chemoreflex function in conscious rabbits with pacing-induced heart failure. J Appl Physiol 1999; 86: 1264-1272.

13. Solin P, Bergin P, Richardson M, Kaye DM, Walters $\mathrm{EH}$, Naughton MT. Influence of pulmonary capillary wedge pressure on central apnoea in heart failure. Circulation 1999; 99: 1574-1579.

14. Sin D, Fitzgerald F, Parker JD, Newton G, Floras JS, Bradley TD. Risk factors for central and obstructive sleep apnoea in 450 men and women with congestive heart failure. Am J Respir Crit Care Med 1999; 160: 1101-1106. 